the decomposition of aldehydes and ketones that both of the bonds between the carbonyl group and the two groups attached to it are broken practically simultaneously, the two groups then, in general, uniting to form a saturated paraffin ${ }^{2}$.

During an investigation of the photo-decomposition of di-ethyl-peroxide, we have found that the chief products are ethyl alcohol and a greenish-yellow substance which has been finally determined to be diacetyl. Little if any acetaldehyde was produced, at any rate during the early stages of the decomposition. The decomposition was very slow, and although no measurements of the quantum yield have been attempted, a chain reaction would seem improbable.

The formation of ethyl alcohol and diacetyl can be accounted for by a mechanism based on that of Haber and Willstätter ${ }^{3}$ for enzyme oxidations and also employed by Taylor and Gould to explain the oxidation of ethyl alcohol photo-sensitised by hydrogen peroxide ${ }^{4}$;

$$
\begin{aligned}
\mathrm{CH}_{8} \cdot \mathrm{CH}_{2}-\mathrm{O}-\mathrm{O}-\mathrm{CH}_{2} \mathrm{CH}_{8}+h v \rightarrow 2 \mathrm{CH}_{8} \cdot \mathrm{CH}_{2} \cdot \mathrm{O}- \\
\mathrm{CH}_{8} \cdot \mathrm{CH}_{2} \cdot \mathrm{O}-+\mathrm{CH}_{3} \mathrm{CH}_{2}-\mathrm{O}-\mathrm{O}-\mathrm{CH}_{2} \mathrm{CH}_{3} \rightarrow 2 \mathrm{C}_{2} \mathrm{H}_{5} \mathrm{OH}+\mathrm{CH}_{8} \mathrm{CO} \\
2 \mathrm{CH}_{8} \mathrm{CO} \rightarrow\left(\mathrm{CH}_{2} \mathrm{CO}\right)_{2} .
\end{aligned}
$$

Such a mechanism necessitates a somewhat longlived acetyl radical. In order to obtain further evidence for this, we have examined the non-gaseous products of the decomposition of the three simplest ketones and acetaldehyde. In all cases the products were of a greenish-yellow colour, which was, however, only faint with diethyl-ketone and acetaldehyde.

The products from acetone and methylethyl. ketone yielded with dinitro-phenylhydrazine $a$ few milligrams of a substance almost insoluble in boiling alcohol (and therefore readily separable from the ketone derivative) but which could be recrystallised from pyridine. A derivative with similar solubilities was also obtained from the acetone product with mono-nitro-phenylhydrazine. In all cases the physical properties of these derivatives agreed with those of the corresponding derivative of diacetyl. Damon and Daniels have also observed that the liquid products from the photo-decomposition of acetone are coloured.

While far from being conclusive, this evidence would seem strongly to suggest that the acetyl radical is much more stable than is usually assumed, and that it possibly plays a significant rôle in the photo-decomposition of acetaldehyde and acetone at room temperature.

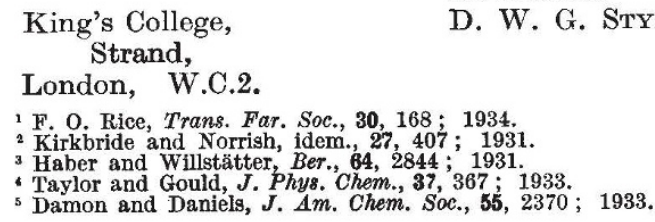

\section{Diffusion of Gases through Metals}

I HAVE read with interest the letter by Dr. Smithells and Mr. Ransley on the diffusion of gases through metals in NaTURE of November 24. I agree with them that diffusion is dependent on the solubility of gases in metals, and that the approximate proportionality to $\sqrt{ } P$ is related to the fact that sorbed hydrogen is not only monatomic, but also ionised, as pointed out by $\mathrm{me}^{2}$ and by A. Coehn ${ }^{2}$.
Further, adsorption on the surface must be distinct from absorption within the metal. Absorption must be considered in the study of diffusion, just as Fourier and Poisson took account of specific heat in their classical equations for thermal conductivity.

In occlusion and diffusion, the hydrogen is in the form of protons (or deutons). I think the condensa. tion of molecules on the metal surface, due to electrostatic attraction, produces electronic perturbations in the surface metal atoms (as shown by the effect on the photo-electric properties), which facilitates the diffusion of the gas. The effect of the adsorbed film can therefore only extend to a distance of one atomic diameter, and the mobility of protons within the metal will not depend on adsorption, but on the particular atomic arrangement of the metal and on the concentration gradient of absorbed hydrogen.

An equilibrium exists between the adsorbed gas and the gas absorbed near the surface, in which the two concentrations have a fixed ratio for each gasmetal system. Diffusion therefore depends on many factors. The proportionality between diffusion and $\sqrt{ } P$ can be readily interpreted theoretically. The deviation from this law can be tentatively explained either by assuming an adsorption pressure threshold on one side and an evaporation pressure threshold on the other side of the metal ; or alternatively, as suggested by Smithells and Ransley. The hypothesis can be tested by considering the behaviour of palladium towards hydrogen and deuterium.

From experiments which are still proceeding and will be published elsewhere, I have been able to show that palladium adsorbs deuterium very considerably from a mixture of hydrogen and deuterium, whereas it is well known that deuterium diffuses very slowly, in comparison with hydrogen, through palladium.

$$
\begin{gathered}
\text { Istituto di Fisica, } \\
\text { R. Università, } \\
\text { Pavia. } \\
\text { Dec. 15. }
\end{gathered}
$$

Tito Franzint.

1. T. Franzini, Rend. R. Ist. Lomb., 709; 1931. N. Cim., No. 9 ; 1931. ${ }^{2}$ A. Coehn, Z. Phys., 62, 1; 1930. 71, 79; 1931. 83, 291; 1933

\section{Molecular Spectrum of Cadmium Vapour}

Is a recent article on the above subject, $\mathrm{S}$. Winston Cram $^{1}$ has reported his inability to obtain, either in fluorescence or by excitation with a Tesla coil, a narrow diffuse cadmium band at 2212. He concludes that the band in that region which I obtained some years ago $^{2}$, using a pure electrodeless discharge in low pressure vapour, must be due to an impurity.

During a year's leave of absence, when working in the astrophysics laboratory of the Imperial College of Science and Technology, I made a careful examination of the molecular spectrum of cadmium. Although a full account of this work will be published later, in this letter I should like to direct attention to the following results relating to the origin of the band in question.

(1) As is shown by the spectra reproduced in Fig. 1, an arc between cadmium electrodes emits a band at 2212 with an intensity greater than that of the emission band at 2125. This was first noticed in a few cadmium plates given me by $H$. G. Howell, of Armstrong College, Newcastle-on-Tyne. On trying 